Fig. $3 \alpha-\alpha^{\prime}$ System

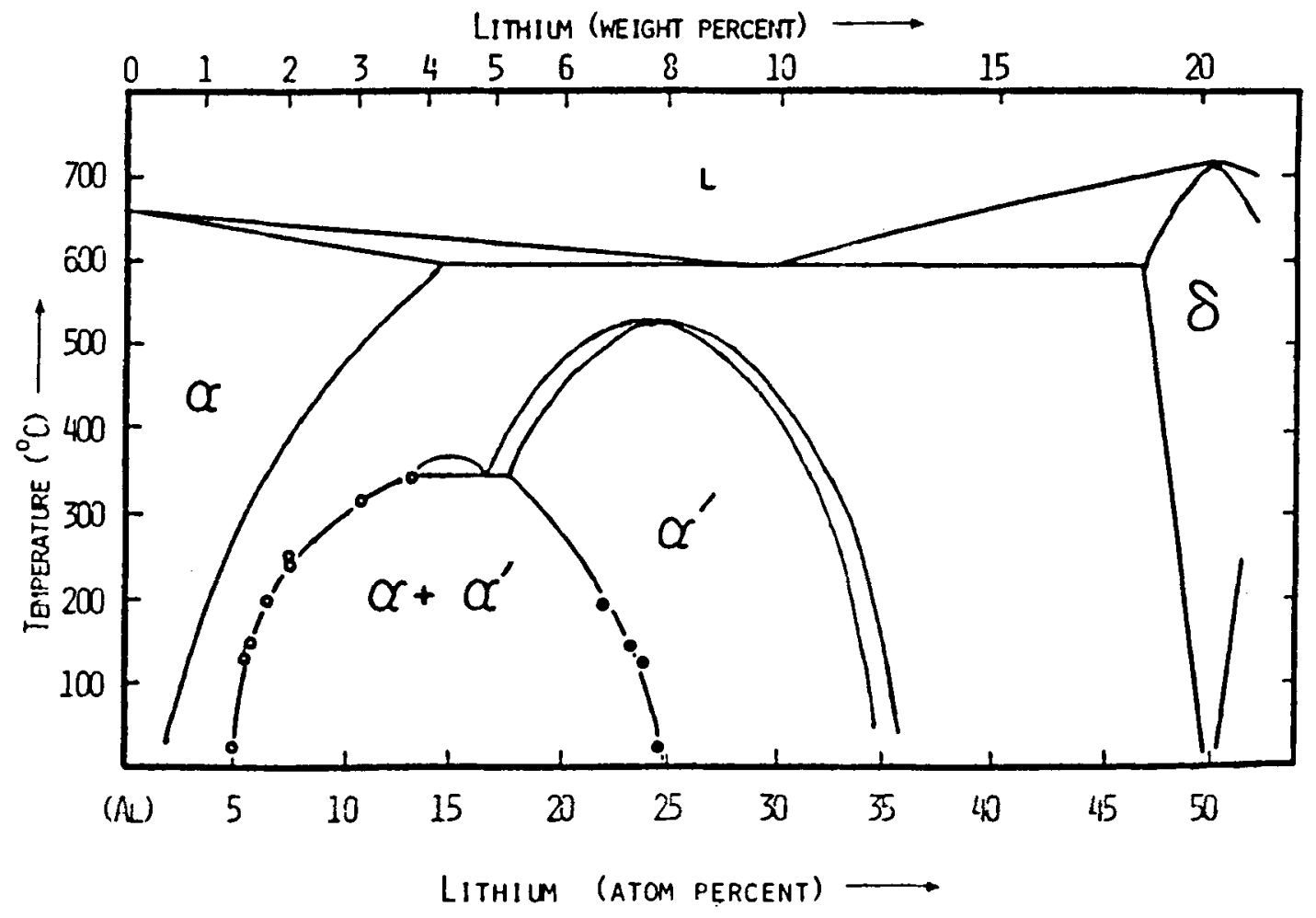

As proposed by F. W. Gayle and J. B. Vander Sande.

\title{
Addenda
}

\section{Age Hardening of Aluminum Alloy}

I am indebted to Cyril Stanley Smith for pointing out to me that discovery of the age hardening of aluminum alloy occurred in Sep 1906, not 1904 as mentioned in my recent article [83Cah]. The source of the 1906 date is a note in Aluminium (Düsseldorf), "How Duralumin was Discovered", Vol. 18, p 366 (1936) based on an interview with Wilm and signed hs. (An English translation is provided by Hunsicker and Stumpf, Ref 3.) A biography of Wilm by M. H. Haas, in Aluminium, Vol. 17, p 502 (1935) gives the date as 1907 . Wilm had been working on strengthening aluminum for several years. Three prior German patents on heating and quenching various aluminum alloys attributed to Wilm, but granted in the name of his organization, were submitted Oct 20, 1903 (No. 170, 085), Nov 11, 1905 (No. 181, 737) and Jan 11, 1907 (No. 204, 543). The age hardening patent (No. 244, 554) was not submitted until March 20,1909, and it was granted March 9, 1912. Wilm's article in Metallurgie appeared in 1911 , but was preceded in 1910 by one by L. M. Cohen on "Duralumin" in Ver. Z. Förd, d. Gewerbefleissen.

\section{References}

83Cah: J.W. Cahn, "A Historical Perspective on the Utilization of Phase Diagrams for Precipitation Hardening", Bull. Alloy Phase Diagrams, 4(4), 349-351 (1983).

Above remarks by

J. W. Cahn

National Bureau of Standards

\section{Silver Rare-Earth Systems}

In the introductory article to the silver rare-earth systems in Vol. 4, No. 4, p 365, the horizontal axis labels of Fig. 1 and 2 were reversed. The composition of Fig. 1 is in atomic percent and Fig. 2 is in weight percent.

\section{The Al-Ga (Aluminum-Gallium) System}

In Vol. 4 , No. 2 , p 187, Table 7 , the eight temperature values, 660 to $875^{\circ} \mathrm{C}$, should read $727^{\circ} \mathrm{C}$.

\section{The Sn-Zr (Tin-Zirconium) System}

In Vol. 4, No. 2, the last line of the first column on $p 153$ should read " $3890 \mathrm{~J} / \mathrm{mol}$ and $18830 \mathrm{~J} / \mathrm{mol}$, respectively [76Alc]".

\section{The Al-Li (Aluminum-Lithium) System}

The following changes should be made to the Al-Li system in Vol. 3, No. 2, p 177-182: (1) the subcaption to Fig. 3, p 180 should read $\otimes \equiv$ [78Cer]; (2) in Table 9, p 182, the equations in the statement should read, "For 0.7 at.\% $\mathrm{Li}, a_{\mathrm{Li}}=\exp [-3.099-6299 /(T+273)]$; for 5.6 at.\% $\mathrm{Li}, a_{\mathrm{Li}}=\exp [-0.951-3809 /(T+273)]$;" and (3) in Table 12, p 182, the AlLi compound ( $\beta$ phase) parameters should be $F_{\mathrm{LiAl}}, C_{\mathrm{LiAl}}, D_{\mathrm{LiAl}}$. 